\title{
Calibration of the exponential Ornstein-Uhlenbeck process when spot prices are visible through the maximum log-likelihood method. Example with gold prices
}

\section{Carlos Armando Mejía Vega ${ }^{1^{*}}$}

\section{${ }^{*}$ Correspondence:}

carlos.mejia@uexternado.edu.co ${ }^{1}$ Externado University of Colombia, Bogota, Colombia

\section{Springer}

\begin{abstract}
The purpose of this paper is to present a methodological procedure to estimate the parameters of the exponential Ornstein-Uhlenbeck process, also known as the Schwartz (J. Finance 52(3):923-973, 1997) one-factor model, in situations where the spot price of the commodity is observable. The proposal consists of looking at the probability function of the process as a function of the unknown parameters in discrete time, known as the likelihood function. Then the logarithm of that expression is calculated as it is easier to work with it. Finally, the problem of determining the values of the parameters that maximize the sum of the individual log-likelihoods (joint log-likelihood function) is solved to obtain the estimation equations explicitly. In that sense, this work is relevant because as spot prices are available, it is possible to estimate the parameters directly without the necessity of using more elaborate approaches like the Kalman filter. Finally, the paper applies this methodology to the concrete case of one precious metal that has an observable spot price and for which some empirical and theoretical studies suggest that it presents a mean-reverting pattern, gold. The estimated parameters are consistent with previous works and with the original data and the least squares method.
\end{abstract}

JEL Classification: C100; C130; G100; G170

Keywords: Commodities; Commodity modelling; Stochastic process; Exponential Ornstein-Uhlenbeck process; Maximum log-likelihood method; Parameters estimation

\section{Introduction}

Commodities are the essential blocks of humanity, as they are raw materials that are fundamental to both the sustainability and development of any civilization. Furthermore, many countries specialize in their exportation in international physical markets, which implies that any movement in commodity prices can have significant consequences for them [11]. Finally, in recent years, global commodity financial markets have been rapidly expanding, and commodity futures are nowadays essential assets in any investor portfolio around

(c) The Author(s) 2018. This article is distributed under the terms of the Creative Commons Attribution 4.0 International License (http://creativecommons.org/licenses/by/4.0/), which permits unrestricted use, distribution, and reproduction in any medium, provided you give appropriate credit to the original author(s) and the source, provide a link to the Creative Commons license, and indicate if changes were made. 
the world [32]. Considering all these facts, commodity price analysis and modeling have turned into relevant fields nowadays.

One of the main distinguishing features of most commodity prices against other asset prices is the presence of a mean-reverting behavior (see, e.g., Bessembinder et al. [4], Casassus and Collin-Dufresne [7], Pyndick [21], Routledge et al. [25], and Schwartz [27], among others, for empirical evidence justifying the usage of mean-reversion for commodity prices). Based on this, commodity modeling has been applying models with this property since long time ago [1]. In that sense, the most basic and simplified stochastic process that describes the characteristic of the process to drift toward a long-term value is known as the Ornstein-Uhlenbeck process [8]. It was first used in commodity modeling by Gibson and Schwartz [12] to model the light sweet (WTI) crude oil net spot instantaneous convenience yield under the umbrella of the storage theory (see Lautier [18] for a complete survey of the storage theory till the models of Schwartz [27]).

The Ornstein-Uhlenbeck process (also known as the arithmetic Ornstein-Uhlenbeck process) is a stochastic process initially proposed by the physicists Leonard Solomon Ornstein and the physicist George Eugene Uhlenbeck in a paper titled On the theory of the Brownian motion [33]. This work appeared in volume 36 of the Physical Review in September 1930. In general terms, and under a filtered probability space $\left[\Omega, \mathcal{F},\left(\mathcal{F}_{t \geq 0}\right), \mathbb{P}\right]$, a stochastic process $\{X(t) ; t \geq 0\}$ is said to follow an arithmetic Ornstein-Uhlenbeck process if it satisfies the following stochastic differential equation [19]:

$$
d X(t)=\theta[\mu-X(t)] d t+\sigma d W(t)
$$

where $d X(t)$ is an increment of the process $X$ between $t$ and $d t$, and $\sigma>0$ is the instantaneous diffusion term, used to measure the volatility of the process, which is assumed to be constant. On the other side, $\mu$ is the process long-term expected value, and $\theta>0$ is the speed or reversion of $X(t)$ toward $\mu$, both also assumed to be constant. Finally, $d W(t)$ is an increment during the interval $(t, t+d t)$ of a standard Brownian motion under the real probability measure $\mathbb{P}$, which follows a normal distribution with expected value 0 and variance $t$.

Several works have used the Ornstein-Uhlenbeck process to model directly the dynamics over time of different commodity spot prices under the umbrella of the so-called reduced-form one-factor models (for a review of the differences between reduced-form and equilibrium-structural models in commodity modeling, see Ribeiro and Hodges [22]). Chaiyapo and Phewchean [8] constitutes a recent study in that sense. In fact, they used this stochastic process to model the Thai commodity market. Explicitly, they modeled three types of agricultural commodities (Tapioca Starch, Ribbed Smoke Sheet No. 3, and Thai Horn Mali Rice) and used futures prices from the Agricultural Futures Exchange of Thailand (AFET) as proxies of the spot prices. Another recent work is that by Tanaka and Carrasco Montero [31], who used it to model gold spot prices for valuing a mine investment project under the real options approach in Peru. Finally, the Ornstein-Uhlenbeck process has been used to model electricity prices alone or with other components (see, e.g., Barlow [1], who used it to later derive a nonlinear Ornstein-Uhlenbeck process by making certain assumptions about the functional form of the supply and demand curve and then applied it to electricity prices of both Alberta and California electricity markets).

In all these cases, to make forecasts, it was essential to calibrate the model (that is, to estimate its parameters). In that sense, there are three accepted methods: least squares [30], 
maximum log-likelihood [34], and jackknife technique [20]. Based on this, Chaiyapo and Phewchean [8] calibrated their model with the three methods, whereas Tanaka and Carrasco Montero [31] used only the least squares method, and Barlow [1] the log-likelihood one. However, even if the parameters were consistent, one of the general limitations is that in all these cases, spot prices can have negative values.

By considering this, and inspired by Ross [24] and Bessembinder et al. [4], the engineer Eduardo Schwartz proposed a modification of the geometric Ornstein-Uhlenbeck developed previously by Dixit and Pyndick [10] in a paper titled The stochastic behavior of commodity prices: Implications for valuation and hedging. This model, known as the Schwartz [27] reduced-form, equilibrium one-factor model or as the exponential Ornstein-Uhlenbeck process [3], appeared in volume 52 of The Journal of Finance in July 1997. In general terms, and under a filtered probability space $\left[\Omega, \mathcal{F},\left(\mathcal{F}_{t \geq 0}\right), \mathbb{P}\right]$, a stochastic process $\{X(t) ; t \geq 0\}$ is said to follow an exponential Ornstein-Uhlenbeck process if it satisfies the following stochastic differential equation [27]:

$$
d X(t)=\theta\{\hat{\mu}-\operatorname{Ln}[X(t)]\} X(t) d t+\sigma X(t) d W(t)
$$

where $d X(t)$ is an increment of the process $X$ between $t$ and $t+d t, \hat{\mu}$ and $\theta>0$ are two constants that affect the instantaneous drift component of the process, and $d t$ is an infinitesimal increment in time. On the other side, $\sigma>0$ is a third constant that affects the instantaneous diffusion component of the process. Finally, $d W(t)$ is an increment, during the interval $(t, t+d t)$, of a standard Brownian motion under the real probability measure $\mathbb{P}$, which follows a normal distribution with expected value 0 and variance $t$.

This model has also been used to describe and simulate the general mean-reverting dynamic over time of several commodities spot prices again under the umbrella of the reduced-form one-factor models. In fact, Schwartz [27] applied it for WTI crude oil and for gold and copper. A more recent work of Bastian-Pinto et al. [2] used the same stochastic process to model alternative fuels in Brazil into the real options framework. Explicitly, they modeled two types of agricultural commodities (sugar and ethanol). Finally, Brajkovic [6] used this model (as well as the geometric Brownian motion, arithmetic OrnsteinUhlenbeck process, and Cox-Ingersoll-Ross process) for modeling coal prices and valued a baseload coal-fired power plant under the same real options approach.

With this second model, to make forecasts again, it was also essential to calibrate the model. However, by recognizing the fact that spot prices are not visible (mostly in international commodity markets), Schwartz [27] decided to calibrate the model by relating the spot price with futures prices (which are visible) and then applying a filtering process known as the Kalman filter (for a detailed discussion of the state space models and the Kalman filter, see Harvey [13]) combined with the maximization of a defined joint loglikelihood function. This method is known as the expectation maximization algorithm or the prediction error decomposition (see Harville [14]). Since then, it is the standard procedure to estimate the parameters of this model (see, e.g., Kellerhals [15]).

However, some commodities, in fact, have an observable spot price (even in the international commodity financial markets). It is the case of most precious metals like gold, silver, platinum, and palladium with their respective spot exchange rates against some currencies like the United States dollar [29]. Also, the Kalman filter presents some essential limitations regarding local minimums as indicted by Sauvageau and Kumral [26]. Based on this, 
it could be possible to estimate the parameters by more suitable and tractable methods like the ones mentioned before for the traditional arithmetic Ornstein-Uhlenbeck process. In that sense, Dias [9] applied the least squares method for the exponential OrnsteinUhlenbeck process and obtained the calibration equations explicitly. However, the calibration of this process through the log-likelihood approach has not been entirely developed and analyzed in commodity modeling. In that sense, Brajkovic [6] estimated the parameters of the four models mentioned before to see which ones fit better for coal prices through the joint likelihood function method, but only defined the general problem and used computational ways to solve it in each case.

Based on this, in this paper, we expose a calibration method that does not require the use of filtering processes like the Kalman filter, but only the maximization of a defined joint log-likelihood function. The structure of the paper goes in the following way. In Sect. 1, general information about the literature is given. In Sect. 2, a general presentation of the stochastic process is provided. In Sect. 3, the exposition of the general estimation procedure is presented. In Sect. 4, the method is applied to gold prices, and finally, in the last section, both the conclusion and discussion for futures works are included.

\section{The exponential Ornstein-Uhlenbeck process}

\subsection{Intuition as a deterministic process}

A deterministic process $X(t)$ is said to follow a deterministic exponential OrnsteinUhlenbeck process if it satisfies the following differential equation:

$$
d X(t)=\theta\{\hat{\mu}-\operatorname{Ln}[X(t)]\} X(t) d t
$$

where the drift term depends on the natural logarithm of the current value of the process $\operatorname{Ln}[X(t)]$, and the natural logarithm of the long-term expected value of the spot price $\hat{\mu}$ acts as the equilibrium level of the process:

- If the natural logarithm of the current value of the process $\operatorname{Ln}[X(t)]$ is lower than $\hat{\mu}$, then the drift will be positive, $\theta\{\hat{\mu}-\operatorname{Ln}[X(t)]\} X(t)>0$ and $d X(t)>0$.

- If the natural logarithm of the current value of the process $\operatorname{Ln}[X(t)]$ is higher than $\hat{\mu}$, then the drift will be negative, $\theta\{\hat{\mu}-\operatorname{Ln}[X(t)]\} X(t)<0$ and $d X(t)<0$.

- This dynamics is known as mean-reverting, where $\theta>0$ determines the speed of reversion of the process.

\subsection{Analytical solution}

Considering that $X(t)$ is an Itô process and applying Itô's lemma to the function $\operatorname{Ln}[X(t)] e^{\theta t}$, we get:

$$
d\left\{\operatorname{Ln}[X(t)] e^{\theta t}\right\}=\left(\theta \hat{\mu} e^{\theta t}-\frac{\sigma^{2} e^{\theta t}}{2}\right) d t+\sigma e^{\theta t} d W(t) .
$$

Given equation (4), the integration from $s$ to $t$, where $0 \leq s<t$, is performed to obtain the analytical solution of equation (2) [27]:

$$
\operatorname{Ln}[X(t)]=\operatorname{Ln}[X(s)] e^{-\theta(t-s)}+\left(\hat{\mu}-\frac{\sigma^{2}}{2 \theta}\right)\left[1-e^{-\theta(t-s)}\right]+\int_{s}^{t}\left[\sigma e^{-\theta(t-u)}\right] d W(u) .
$$




\subsection{Gaussian property}

From equation (5) the expected value and the variance of the process $\operatorname{Ln}[X(t)]$, conditional to information $\left(\mathcal{F}_{s}\right)_{t>s \geq 0}$, are given by [27]

$$
\begin{aligned}
& E\left\{\operatorname{Ln}[X(t)] \mid \mathcal{F}_{s}\right\}=\operatorname{Ln}[X(s)] e^{-\theta(t-s)}+\left(\hat{\mu}-\frac{\sigma^{2}}{2 \theta}\right)\left[1-e^{-\theta(t-s)}\right] \\
& \operatorname{Var}\left\{\operatorname{Ln}[X(t)] \mid \mathcal{F}_{s}\right\}=\frac{\sigma^{2}}{2 \theta}\left[1-e^{-2 \theta(t-s)}\right] .
\end{aligned}
$$

From equations (5), (6), and (7) it is possible to conclude that the process $\operatorname{Ln}[X(t)]$, conditional to information $\left(\mathcal{F}_{s}\right)_{t>s \geq 0}$, follows the normal distribution (it is a Gaussian process) with expected value $\operatorname{Ln}[X(s)] e^{-\theta(t-s)}+\left(\hat{\mu}-\frac{\sigma^{2}}{2 \theta}\right)\left[1-e^{-\theta(t-s)}\right]$ and variance $\frac{\sigma^{2}}{2 \theta}\left[1-e^{-2 \theta(t-s)}\right]$. The conditional probability distribution function of $\operatorname{Ln}[X(t)]$ under the exponential OrnsteinUhlenbeck process is given by

$$
\begin{aligned}
& f\{\operatorname{Ln}[X(t)] \mid \theta, \hat{\mu}, \sigma\} \\
& =\frac{1}{\sqrt{2 \pi \frac{\sigma^{2}}{2 \theta}\left[1-e^{-2 \theta(t-s)}\right]}} \\
& \quad \times e\left(-\frac{\left\{\operatorname{Ln}[X(t)]-\operatorname{Ln}[X(s)] e^{-\theta(t-s)}-\left(\hat{\mu}-\frac{\sigma^{2}}{2 \theta}\right)\left[1-e^{-\theta(t-s)}\right]\right\}^{2}}{2\left\{\frac{\sigma^{2}}{2 \theta}\left[1-e^{-2 \theta(t-s)}\right]\right\}}\right) .
\end{aligned}
$$

\section{Parameters estimation through the maximum log-likelihood method}

\subsection{Discretization process}

Given the availability of an information set $\mathcal{F}_{t-1}$ and an observation interval $[0, T]$, the exact analytical solution of the exponential Ornstein-Uhlenbeck process in equation (5) can be discretized over a partition with constant interval $\Delta t=\frac{T}{\text { steps }}$ in the following way:

$$
\operatorname{Ln}\left(X_{t}\right)=\operatorname{Ln}\left(X_{t-1}\right) e^{-\theta \Delta t}+\left(\hat{\mu}-\frac{\sigma^{2}}{2 \theta}\right)\left(1-e^{-\theta \Delta t}\right)+\sigma \sqrt{\frac{1}{2 \theta}\left(1-e^{-2 \theta \Delta t}\right)} \varepsilon_{t},
$$

where $\varepsilon_{t}$ is an error driven by the normal distribution with expected value 0 and variance 1. In that sense, the process $\operatorname{Ln}\left(X_{t}\right)$, conditional to information $\mathcal{F}_{t-1}$, follows the normal distribution with expected value $\operatorname{Ln}\left(X_{t-1}\right) e^{-\theta \Delta t}+\left(\hat{\mu}-\frac{\sigma^{2}}{2 \theta}\right)\left(1-e^{-\theta \Delta t}\right)$ and variance $\frac{\sigma^{2}}{2 \theta}(1-$ $\left.e^{-2 \theta \Delta t}\right)$. Furthermore, equation (9) can be also expressed in the other way:

$$
\operatorname{Ln}\left(X_{t}\right)=\operatorname{Ln}\left(X_{t-1}\right) e^{-\theta \Delta t}+\left(\hat{\mu}-\frac{\sigma^{2}}{2 \theta}\right)\left(1-e^{-\theta \Delta t}\right)+\eta_{t}
$$

where $\eta_{t}$ is an error driven by the normal distribution with expected value 0 and variance $\frac{\sigma^{2}}{2 \theta}\left(1-e^{-2 \theta \Delta t}\right)$. The process $\operatorname{Ln}\left(X_{t}\right)$, conditional to information $\mathcal{F}_{t-1}$, again follows the normal distribution with expected value $\operatorname{Ln}\left(X_{t-1}\right) e^{-\theta \Delta t}+\left(\hat{\mu}-\frac{\sigma^{2}}{2 \theta}\right)\left(1-e^{-\theta \Delta t}\right)$ and variance $\frac{\sigma^{2}}{2 \theta}\left(1-e^{-2 \theta \Delta t}\right)$.

\subsection{The joint log-likelihood function}

The calibration of the exponential Ornstein-Uhlenbeck process can be done through the maximum log-likelihood method by searching the estimates that maximize the joint loglikelihood function using the first-order conditions. Recalling equations (5), (6), (7), (8), 
and (9) or (10), the likelihood function is given by [23]

$$
\mathcal{L}\left[\theta, \hat{\mu}, \sigma \mid \operatorname{Ln}\left(X_{t}\right)\right]=\frac{1}{\sqrt{2 \pi \hat{\sigma}^{2}}} e\left\{-\frac{\left[\operatorname{Ln}\left(X_{t}\right)-\operatorname{Ln}\left(X_{t-1}\right) e^{-\theta \Delta t}-\hat{\hat{\mu}}\left(1-e^{-\theta \Delta t}\right)\right]^{2}}{2 \hat{\sigma}^{2}}\right\}
$$

where

$$
\begin{aligned}
& \hat{\hat{\mu}}=\hat{\mu}-\frac{\sigma^{2}}{2 \theta}, \\
& \hat{\sigma}^{2}=\frac{\sigma^{2}}{2 \theta}\left(1-e^{-2 \theta \Delta t}\right) .
\end{aligned}
$$

However, for practical purposes, it is better to use the log-likelihood function given by

$$
\begin{aligned}
& \operatorname{Ln}\left\{\mathcal{L}\left[\theta, \hat{\mu}, \sigma \mid \operatorname{Ln}\left(X_{t}\right)\right]\right\} \\
& \quad=-\frac{1}{2} \operatorname{Ln}(2 \pi)-\operatorname{Ln}(\hat{\sigma})-\frac{\left[\operatorname{Ln}\left(X_{t}\right)-\operatorname{Ln}\left(X_{t-1}\right) e^{-\theta \Delta t}-\hat{\hat{\mu}}\left(1-e^{-\theta \Delta t}\right)\right]^{2}}{2 \hat{\sigma}^{2}} .
\end{aligned}
$$

Finally, given independent observations $\operatorname{Ln}\left(X_{1}\right), \operatorname{Ln}\left(X_{2}\right), \ldots, \operatorname{Ln}\left(X_{n}\right)$, the joint-log likelihood function is given by

$$
\begin{aligned}
& \sum_{i=1}^{n} \operatorname{Ln}\left\{\mathcal{L}\left[\theta, \hat{\mu}, \sigma \mid \operatorname{Ln}\left(X_{i}\right)\right]\right\} \\
& \quad=-\frac{n}{2} \operatorname{Ln}(2 \pi)-n \operatorname{Ln}(\hat{\sigma})-\frac{1}{2 \hat{\sigma}^{2}} \sum_{i=1}^{n}\left\{\left[\operatorname{Ln}\left(X_{i}\right)-\operatorname{Ln}\left(X_{i-1}\right) e^{-\theta \Delta t}-\hat{\hat{\mu}}\left(1-e^{-\theta \Delta t}\right)\right]^{2}\right\} .
\end{aligned}
$$

\subsection{First-order conditions}

The next step consists in taking the partial derivatives and equal them to zero. In that sense, the partial derivative with respect to $\hat{\hat{\mu}}$ is taken:

$$
\frac{\partial\left\langle\sum_{i=1}^{n} \operatorname{Ln}\left\{\mathcal{L}\left[\theta, \hat{\mu}, \sigma \mid \operatorname{Ln}\left(X_{i}\right)\right]\right\}\right\rangle}{\partial \hat{\hat{\mu}}}=0 .
$$

Development:

$$
\begin{aligned}
& \frac{\partial\left\langle\sum_{i=1}^{n} \operatorname{Ln}\left\{\mathcal{L}\left[\theta, \hat{\mu}, \sigma \mid \operatorname{Ln}\left(X_{i}\right)\right]\right\}\right\rangle}{\partial \hat{\hat{\mu}}} \\
& \quad=\frac{\left(1-e^{-\theta \Delta t}\right)}{\hat{\sigma}^{2}} \sum_{i=1}^{n}\left[\operatorname{Ln}\left(X_{i}\right)-\operatorname{Ln}\left(X_{i-1}\right) e^{-\theta \Delta t}-\hat{\hat{\mu}}\left(1-e^{-\theta \Delta t}\right)\right] .
\end{aligned}
$$

Equal to zero:

$$
\begin{aligned}
& \frac{\left(1-e^{-\theta \Delta t}\right)}{\hat{\sigma}^{2}} \sum_{i=1}^{n}\left[\operatorname{Ln}\left(X_{i}\right)-\operatorname{Ln}\left(X_{i-1}\right) e^{-\theta \Delta t}-\hat{\hat{\mu}}\left(1-e^{-\theta \Delta t}\right)\right]=0, \\
& \hat{\hat{\mu}}=\frac{\sum_{i=1}^{n}\left[\operatorname{Ln}\left(X_{i}\right)\right]-e^{-\theta \Delta t} \sum_{i=1}^{n}\left[\operatorname{Ln}\left(X_{i-1}\right)\right]}{n\left(1-e^{-\theta \Delta t}\right)} .
\end{aligned}
$$


Considering equation (12), we then have:

$$
\hat{\mu}=\hat{\hat{\mu}}+\frac{\sigma^{2}}{2 \theta} \text {. }
$$

Next, the partial derivative with respect to $\theta$ is taken:

$$
\frac{\partial\left\langle\sum_{i=1}^{n} \operatorname{Ln}\left\{\mathcal{L}\left[\theta, \hat{\mu}, \sigma \mid \operatorname{Ln}\left(X_{i}\right)\right]\right\}\right\rangle}{\partial \theta}=0 .
$$

Development:

$$
\begin{aligned}
& \frac{\partial\left\langle\sum_{i=1}^{n} \operatorname{Ln}\left\{\mathcal{L}\left[\theta, \hat{\mu}, \sigma \mid \operatorname{Ln}\left(X_{i}\right)\right]\right\}\right\rangle}{\partial \theta} \\
& \quad=-\frac{e^{-\theta \Delta t} \Delta t}{\hat{\sigma}^{2}} \sum_{i=1}^{n}\left\{\left[\operatorname{Ln}\left(X_{i}\right)-\hat{\hat{\mu}}\right]\left[\operatorname{Ln}\left(X_{i-1}\right)-\hat{\hat{\mu}}\right]-e^{-\theta \Delta t}\left[\operatorname{Ln}\left(X_{i-1}\right)-\hat{\hat{\mu}}\right]^{2}\right\} .
\end{aligned}
$$

Equal to zero:

$$
\begin{aligned}
& -\frac{e^{-\theta \Delta t} \Delta t}{\hat{\sigma}^{2}} \sum_{i=1}^{n}\left\{\left[\operatorname{Ln}\left(X_{i}\right)-\hat{\hat{\mu}}\right]\left[\operatorname{Ln}\left(X_{i-1}\right)-\hat{\hat{\mu}}\right]-e^{-\theta \Delta t}\left[\operatorname{Ln}\left(X_{i-1}\right)-\hat{\hat{\mu}}\right]^{2}\right\}=0, \\
& \theta=-\frac{1}{\Delta t} \operatorname{Ln}\left\{\frac{\sum_{i=1}^{n}\left[\operatorname{Ln}\left(X_{i}\right) \operatorname{Ln}\left(X_{i-1}\right)\right]-\hat{\hat{\mu}} \sum_{i=1}^{n}\left[\operatorname{Ln}\left(X_{i}\right)\right]-\hat{\hat{\mu}} \sum_{i=1}^{n}\left[\operatorname{Ln}\left(X_{i-1}\right)\right]+n \hat{\hat{\mu}}^{2}}{\sum_{i=1}^{n}\left[\operatorname{Ln}\left(X_{i-1}\right)^{2}\right]-2 \hat{\hat{\mu}} \sum_{i=1}^{n}\left[\operatorname{Ln}\left(X_{i-1}\right)\right]+n \hat{\mu}^{2}}\right\} .
\end{aligned}
$$

Finally, the partial derivative with respect to $\hat{\sigma}$ is taken:

$$
\frac{\partial\left\langle\sum_{i=1}^{n} \operatorname{Ln}\left\{\mathcal{L}\left[\theta, \hat{\mu}, \sigma \mid \operatorname{Ln}\left(X_{i}\right)\right]\right\}\right\rangle}{\partial \hat{\sigma}}=0 .
$$

Development:

$$
\begin{aligned}
& \frac{\partial\left\langle\sum_{i=1}^{n} \operatorname{Ln}\left\{\mathcal{L}\left[\theta, \hat{\mu}, \sigma \mid \operatorname{Ln}\left(X_{i}\right)\right]\right\}\right\rangle}{\partial \hat{\sigma}} \\
& \quad=-\frac{n}{\hat{\sigma}}-\frac{1}{\hat{\sigma}^{3}} \sum_{i=1}^{n}\left\{\left[\operatorname{Ln}\left(X_{i}\right)-\operatorname{Ln}\left(X_{i-1}\right) e^{-\theta \Delta t}-\hat{\hat{\mu}}\left(1-e^{-\theta \Delta t}\right)\right]^{2}\right\} .
\end{aligned}
$$

Equal to zero:

$$
\begin{aligned}
-\frac{n}{\hat{\sigma}}- & \frac{1}{\hat{\sigma}^{3}} \sum_{i=1}^{n}\left\{\left[\operatorname{Ln}\left(X_{i}\right)-\operatorname{Ln}\left(X_{i-1}\right) e^{-\theta \Delta t}-\hat{\hat{\mu}}\left(1-e^{-\theta \Delta t}\right)\right]^{2}\right\}=0 \\
\hat{\sigma}^{2}= & \frac{1}{n}\left\{\sum_{i=1}^{n}\left[\operatorname{Ln}\left(X_{i}\right)^{2}\right]-2 e^{-\theta \Delta t} \sum_{i=1}^{n}\left[\operatorname{Ln}\left(X_{i}\right) \operatorname{Ln}\left(X_{i-1}\right)\right]+e^{-2 \theta \Delta t} \sum_{i=1}^{n}\left[\operatorname{Ln}\left(X_{i-1}\right)^{2}\right]\right. \\
& \left.-2 \hat{\hat{\mu}}\left(1-e^{-\theta \Delta t}\right)\left\{\sum_{i=1}^{n}\left[\operatorname{Ln}\left(X_{i}\right)\right]-e^{-\theta \Delta t} \sum_{i=1}^{n}\left[\operatorname{Ln}\left(X_{i-1}\right)\right]\right\}+n \hat{\hat{\mu}}^{2}\left(1-e^{-\theta \Delta t}\right)^{2}\right\}
\end{aligned}
$$


Considering equation (13), we then have:

$$
\sigma^{2}=\hat{\sigma}^{2}\left[\frac{2 \theta}{\left(1-e^{-2 \theta \Delta t}\right)}\right]
$$

\subsection{Final equations}

One of the problems with the last solutions is that each parameter depends on each other. However, by replacing $\theta$ into $\hat{\mu}$ this can be solved:

$$
\hat{\hat{\mu}}=\frac{a}{b},
$$

where

$$
\begin{aligned}
a= & \sum_{i=1}^{n}\left[\operatorname{Ln}\left(X_{i}\right)\right] \sum_{i=1}^{n}\left[\operatorname{Ln}\left(X_{i-1}\right)^{2}\right]-\sum_{i=1}^{n}\left[\operatorname{Ln}\left(X_{i-1}\right)\right] \sum_{i=1}^{n}\left[\operatorname{Ln}\left(X_{i}\right) \operatorname{Ln}\left(X_{i-1}\right)\right], \\
b= & n\left\{\sum_{i=1}^{n}\left[\operatorname{Ln}\left(X_{i-1}\right)^{2}\right]-\sum_{i=1}^{n}\left[\operatorname{Ln}\left(X_{i}\right)\right]\left[\operatorname{Ln}\left(X_{i-1}\right)\right]\right\}-\left\langle\left\{\sum_{i=1}^{n}\left[\operatorname{Ln}\left(X_{i-1}\right)\right]\right\}^{2}\right. \\
& \left.-\sum_{i=1}^{n}\left[\operatorname{Ln}\left(X_{i}\right)\right] \sum_{i=1}^{n}\left[\operatorname{Ln}\left(X_{i-1}\right)\right]\right\rangle .
\end{aligned}
$$

Considering this, all the parameters can be obtained through the following steps:

- Obtain $\hat{\hat{\mu}}$ from (30), (31), and (32).

- Then obtain $\theta$ from (24).

- Then obtain $\hat{\sigma}^{2}$ from (28).

- Then obtain $\sigma^{2}$ from (29).

- Finally, obtain $\hat{\mu}$ from (20).

\section{Results for gold and discussion}

\subsection{Gold spot prices}

The Bretton Woods Conference (also known as the United Nations Monetary and Financial Conference) established a permanent exchange rate between one troy ounce of gold and the United States dollar. In 1972 the fixed rate system ended, but the logic of an exchange rate between the precious metal and the currency persisted in what is now known as the XAUUSD in Foreign Exchange Markets (FOREX). This exchange rate acts as a spot price for gold [29]. Daily gold spot prices from January 02, 1975, to December 29, 2017, are shown in Fig. 1. These data were taken from Bloomberg. On the other side, the natural logarithm and the logarithm returns of this series are exhibited in Fig. 2 and Fig. 3, respectively.

The descriptive statistics of the gold spot price, its natural logarithm, and the logarithm returns both daily and annually (by taking the annual average) are exhibited in Table 1 and Table 2, respectively. The arithmetic mean of the spot price is around of 577 United States dollars per troy ounce of gold in daily terms and of 574 United States dollars per troy ounce of gold in annual, whereas the logarithm returns exhibit an annual standard deviation of $19 \%$. 


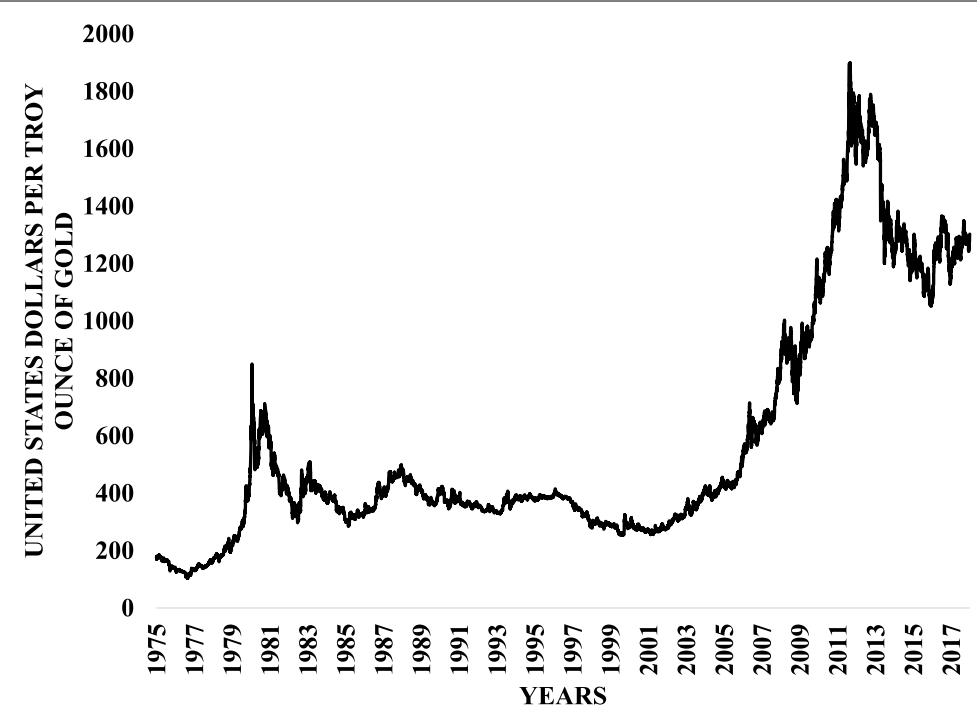

Figure 1 Daily gold spot price from January 02, 1975, to December 29, 2017. Source of data: Bloomberg XAUUSD Currency

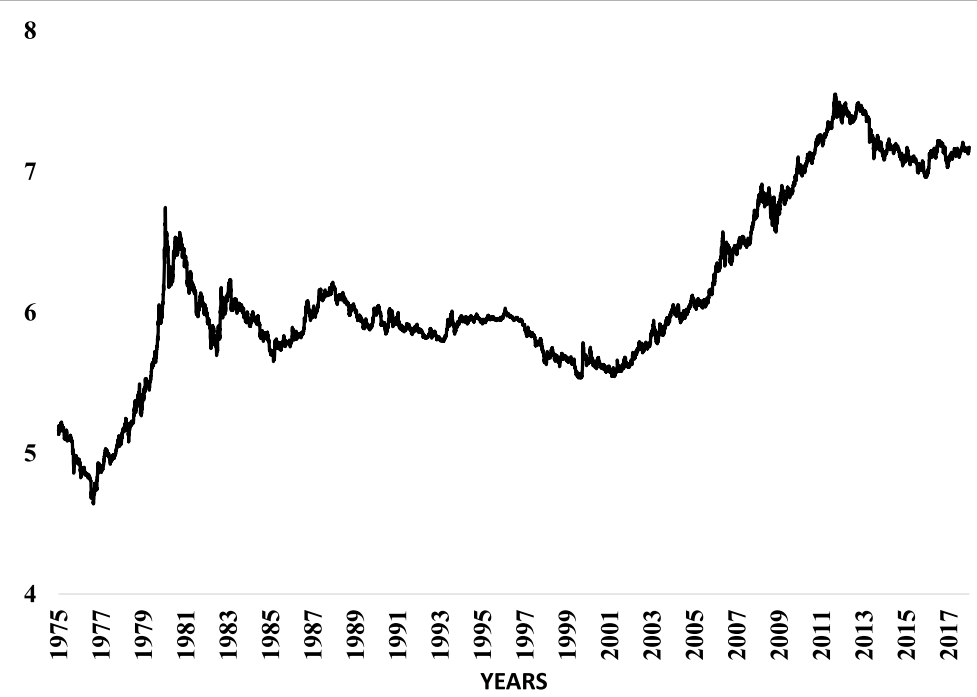

Figure 2 Natural logarithm of the daily gold spot price from January 02, 1975, to December 29, 2017. Source of data: Bloomberg XAUUSD Currency

\subsection{Calibration process}

The choice of the stochastic process to represent the uncertainties can be supported by theoretical considerations referenced in the economic theory and by previous works that applied statistical tests. In that sense, according to microeconomic theory, in the longterm, the spot price of a commodity should be tied to its long-term marginal production cost (see Laughton and Jacoby [17]). The latter means that commodities spot prices tend to revert to a long-term value, besides random short-term fluctuations. On the other side, Bessembinder et al. [4] used econometric tests to analyze future trends of several commodities. They found high mean-reversion patterns for both oil and agriculture prices, whereas weak ones for precious metals. Furthermore, and specifically for gold prices, 


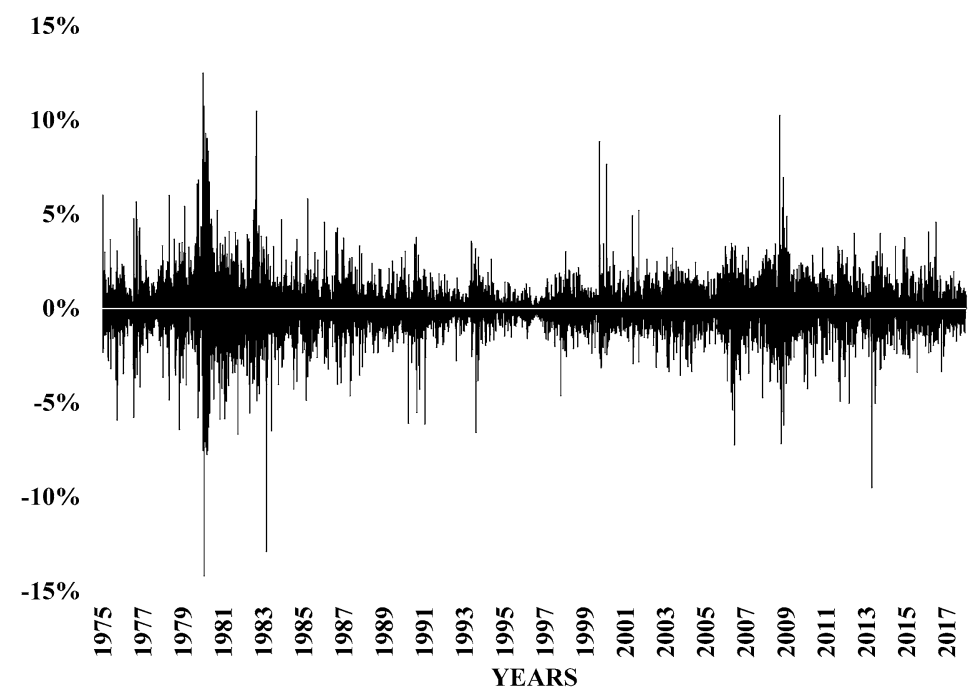

Figure 3 Daily logarithm returns of the gold spot price from January 02, 1975 to December 29, 2017. Source of data: Bloomberg XAUUSD Currency

Table 1 Descriptive statistics of the daily gold spot price, its natural logarithm, and its logarithm returns. Source: Data from Bloomberg XAUUSD

\begin{tabular}{lccc}
\hline Daily & Standard Spot Price & Natural Logarithm & Logarithm return \\
\hline Mean & 577.27 & 6.14 & $0.02 \%$ \\
Standard deviation & 416.02 & 0.65 & $1.23 \%$ \\
Skewness & 1.30 & 0.38 & 0.02 \\
Kurtosis & 3.46 & 2.56 & 14.45 \\
\hline
\end{tabular}

Table 2 Descriptive statistics of the annual gold spot price, its natural logarithm, and its logarithm returns. Source: Data from Bloomberg XAUUSD

\begin{tabular}{lccc}
\hline Annual & Standard Spot Price & Natural Logarithm & Logarithm return \\
\hline Mean & 573.70 & 6.14 & $4.90 \%$ \\
Standard deviation & 415.65 & 0.65 & $19.07 \%$ \\
Skewness & 1.34 & 0.41 & 0.97 \\
Kurtosis & 3.56 & 2.67 & 5.23 \\
\hline
\end{tabular}

Shafee and Topal [28] found that the first difference of gold spot price was stationary, suggesting a mean-reversion pattern. Based on these past studies, it is possible to think that the exponential Ornstein-Uhlenbeck process could be a good model for the gold spot price.

The next step is to calibrate the exponential Ornstein-Uhlenbeck process with the daily data presented in Sect. 4.1 by taking $\Delta t=1$ (to obtain daily parameters) applying equations (30), (31), (32), (24), (28), (29), and (20). Then, the same procedure is repeated but now setting $\Delta t=1 / 250$ (to obtain annualized parameters). Finally, the calibration is done with the average annual data by taking again $\Delta t=1$ (to obtain annual parameters). The results are presented in Table 3.

By looking at Table 3 the annualized and annual parameters are similar, suggesting that it is possible to obtain parameters of different periodicities from the daily data just by 
Table 3 Parameters of the exponential Ornstein-Uhlenbeck process obtained for the gold spot price through the maximum log-likelihood method

\begin{tabular}{lllr}
\hline & Miu hat & Theta & Sigma \\
\hline Daily & 7.22 & 0.0002 & $1.23 \%$ \\
Annualized & 7.67 & 0.0420 & $19.42 \%$ \\
Annual & 7.49 & 0.0497 & $19.06 \%$ \\
\hline
\end{tabular}

changing the $\Delta t$ with little significant errors for the case of gold. Furthermore, some general conclusions are the following:

- The reversion speed $\theta$ indicates that the natural logarithm of the gold spot price (and hence the price) reverts to its long-term expected value in around $\frac{1}{0.0497}$ years or 20 years (for the daily and annualized parameters it will be $\frac{1}{0.0002 * 250}$ or $\frac{1}{0.0420}$ years, equal in both cases to almost 24 years). This low speed of reversion is consistent with previous research works like those of Schwartz [27], Bessembinder et al. [4], Shafee and Topal [28], and Tanaka and Carrasco [31].

- On the other side, both the annualized and annual volatilities are of around 19\%, which confirms gold as having moderate price volatility, and it is consistent with the historical annual standard deviation of the logarithm returns provided before in Table 2, reflecting the consistency of the calibration process again.

\subsection{Comparison with the least squares method}

To see if the obtained parameters are not only consistent with previous works and the information itself, they were also estimated through the least squares method developed by Dixit and Pyndick [10] and modified by Dias [9]. However, in this case, the regression was constructed by following equation (10), so that it relates the natural logarithm of the spot price (rather than the logarithm return) with the natural logarithm of the first lag in the same way Van den Berg [34] did for the arithmetic Ornstein-Uhlenbeck process. The regression equation is then given by

$$
\operatorname{Ln}\left(S_{t}\right)=a \operatorname{Ln}\left(S_{t-1}\right)+b+\eta_{t}
$$

where

$$
\begin{aligned}
& a=e^{-\theta \Delta t}, \\
& b=\hat{\hat{\mu}}\left(1-e^{-\theta \Delta t}\right), \\
& \hat{\hat{\mu}}=\hat{\mu}-\frac{\sigma^{2}}{2 \theta}, \\
& \operatorname{Std}\left(\eta_{t}\right)=\sigma \sqrt{\frac{\left(1-e^{-2 \theta \Delta t}\right)}{2 \theta} .}
\end{aligned}
$$

Rewriting the equations gives

$$
\begin{aligned}
& \theta=-\frac{\operatorname{Ln}(a)}{\Delta t}, \\
& \hat{\hat{\mu}}=\frac{b}{(1-a)},
\end{aligned}
$$


Table 4 Coefficients of the exponential Ornstein-Uhlenbeck process obtained for the gold spot price through the least squares method

\begin{tabular}{lllr}
\hline & $a$ & $b$ & $\operatorname{Std}(\eta)$ \\
\hline Daily & 0.9998 & 0.0012 & $1.23 \%$ \\
Annual & 0.9515 & 0.3451 & $19.06 \%$ \\
\hline
\end{tabular}

Table 5 Parameters of the exponential Ornstein-Uhlenbeck process obtained for the gold spot price through the least squares method

\begin{tabular}{lllr}
\hline & Miu hat & Theta & Sigma \\
\hline Daily & 7.22 & 0.0002 & $1.23 \%$ \\
Annualized & 7.22 & 0.0420 & $19.42 \%$ \\
Annual & 7.12 & 0.0497 & $19.53 \%$ \\
\hline
\end{tabular}

$$
\begin{aligned}
& \sigma=\operatorname{Std}\left(\eta_{t}\right) \sqrt{\frac{-2 \operatorname{Ln}(a)}{\Delta t\left(1-a^{2}\right)}}, \\
& \hat{\mu}=\hat{\hat{\mu}}+\frac{\sigma^{2}}{2 \theta} .
\end{aligned}
$$

The next step is to calibrate the exponential Ornstein-Uhlenbeck process with the daily data presented in Sect. 4.1 by taking $\Delta t=1$ (to obtain daily parameters), by running the regression of equation (33), and finally applying equations (38), (39), (40), and (41). Then, the same procedure is repeated but now setting $\Delta t=1 / 250$ (to obtain annualized parameters). Finally, the calibration is done with the average annual data and by taking again $\Delta t=1$ (to obtain annual parameters). The results of the coefficients $a$ and $b$ and of the standard deviation of the error for both daily and annual data are presented in Table 4. On the other side, the estimated parameters are shown in Table 5.

By looking at Table 5 it is possible to conclude that the three parameters are similar in daily, annualized, and annual terms, and so the proposed methodology is also consistent with the least squares method.

\section{Conclusions}

One of the main difficulties in commodity modeling is the estimation of the parameters of the stochastic processes used to model the dynamics over time of both the spot price and other state variables. One of the main reasons for this is the fact that most of these state variables are not observable for many commodities (mainly in international markets). In that sense, the calibration of general processes like the exponential Ornstein-Uhlenbeck process is done through filtering algorithms like the Kalman filter.

However, for some commodities, like most precious metals, there is an observable spot price, which influences the search for more explicit and straightforward methods of calibration for processes like the exponential Ornstein-Uhlenbeck process that considers the spot price as the only state variable. Based on this assumption, in this paper, we derive the general equations that allow calibrating the model through the log-likelihood methods. Those expressions were possible to obtain, besides the availability of the spot price, because the probability function of the process was known, a fact that enables to construct the joint log-likelihood function and to search for the values of the parameters that maximize that expression. Finally, the parameters obtained for the spot price of gold were consistent with the historical data and with previous studies and the least squares method. 
Futures works might include restrictions to some of the parameters, as some of them cannot have negative values and the present methodology does not impose those conditions. Also, as the maximum log-likelihood method produces a punctual estimator for each parameter, further extensions could be to define intervals for each estimator given a confidence level.

\section{Acknowledgements}

The author would like to thank the editor and referees for their valuable suggestions, which improved the structure and the presentation of the paper.

\section{Funding}

Not applicable.

\section{Competing interests}

The author declares having no competing interests.

\section{Authors' contributions}

All authors read and approved the final manuscript.

\section{Publisher's Note}

Springer Nature remains neutral with regard to jurisdictional claims in published maps and institutional affiliations.

Received: 26 March 2018 Accepted: 15 June 2018 Published online: 07 August 2018

\section{References}

1. Barlow, M.T.: A diffusion model for electricity prices. Math. Finance 12(4), 287-298 (2002)

2. Bastian-Pinto, C., Brandão, L., Hahn, W.J.: Flexibility as a source of value in the production of alternative fuels: the ethanol case. Energy Econ. 31(3), 411-422 (2009)

3. Benth, F.E., Karlsen, K.H.: A note on Merton's portfolio selection problem for the Schwartz mean-reversion model. Stoch. Anal. Appl. 23(4), 687-704 (2005)

4. Bessembinder, H., Coughenour, J.F., Seguin, P.J., Smoller, M.M.: Mean reversion in equilibrium asset prices: evidence from the futures term structure. J. Finance 50(1), 361-375 (1995)

5. Bona, T., Llansana, J.: Física y Química. Carroggio, Barcelona (1999)

6. Brajkovic, J.: Real-options approach to investment in base load coal fired plant. Working paper (2010)

7. Casassus, J., Collin-Dufresne, P.: Stochastic convenience yield implied from commodity futures and interest rates. J. Finance 60(5), 2283-2331 (2005)

8. Chaiyapo, N., Phewchean, N.: An application of Ornstein-Uhlenbeck process to commodity pricing in Thailand. Adv. Differ. Equ. 2017(1), 179 (2017)

9. Dias, M.: Stochastic processes with focus in petroleum applications, Part 2-mean reversion models. http://marcoagd.usuarios.rdc.puc-rio.br/revers.html\#mean-rev

10. Dixit, A.K., Pindyck, R.S.: Investment Under Uncertainty. Princeton University Press, Princeton (1994)

11. Geman, H.: Commodities and Commodity Derivatives. Wiley, West Sussex (2005)

12. Gibson, R., Schwartz, E.S.: Stochastic convenience yield and the pricing of oil contingent claims. J. Finance 45(3), 959-976 (1990)

13. Harvey, A.C.: Forecasting, Structural Time Series Models and the Kalman Filter. Cambridge University Press, Cambridge (1990)

14. Harville, A.: Decomposition of prediction error. J. Am. Stat. Assoc. 80(389), 132-138 (1985)

15. Kellerhals, B.P.: Financial Pricing Models in Continuous Time and Kalman Filtering. Springer, Berlin (2001)

16. Laguna, A.: Modern Supramolecular Gold Chemistry: Gold-Metal Interactions and Applications. Wiley, Weinheim (2008)

17. Laughton, D.G., Jacoby, H.D.: Reversion, timing options, and long-term decision-making. Financ. Manag. 22(3), 225-240 (1993)

18. Lautier, D.: Term structure models of commodity prices: a review. J. Altern. Invest. 8(1), $42-64$ (2005)

19. Önalan, O.: Financial modelling with Ornstein-Uhlenbeck processes driven by Lévy process. In: Proceedings of the World Congress on Engineering, London (2009)

20. Phillips, P.C.B., Yu, J.: Jackknifing bond option prices. Rev. Financ. Stud. 18(2), 707-742 (2005)

21. Pyndick, R.S.: The dynamics of commodity spot and futures markets: a primer. Energy J. 22(3), 1-29 (2001)

22. Ribeiro, D.R., Hodges, S.D.: Equilibrium model for commodity prices: competitive and monopolistic markets. Working Paper (2004)

23. Rohde, C.A.: Introductory Statistical Inference with the Likelihood Function. Springer, New York (2014)

24. Ross, S.: Hedging long run commitments: exercises in incomplete market pricing. Working paper (1995)

25. Routledge, B.R., Seppi, D.J., Spatt, C.S.: Equilibrium forward curves for commodities. J. Finance 55(3), 1297-1338 (2000)

26. Sauvageau, M., Kumral, M.: Genetic algorithms for the optimization of the Schwartz-Smith two-factor model: a case study on a copper deposit. Int. J. Surf. Min. Reclam. Environ. 32(3), 163-181 (2018)

27. Schwartz, E.S.: The stochastic behavior of commodity prices: implications for valuation and hedging. J. Finance 52(3), 923-973 (1997) 
28. Shafiee, S., Topal, E.: An overview of global gold market and gold price forecasting. Resour. Policy 35(3), 178-189 (2010)

29. Sjaastad, L.A.: The price of gold and the exchange rates: once again. Resour. Policy 33(2), 118-124 (2008)

30. Smith, W.: On the simulation and estimation of mean-reverting Ornstein-Uhlenbeck process: especially as applied to commodities markets and modelling (2010)

31. Tanaka, A.T., Carrasco, C.M.: Valorización de opciones reales: el modelo Ornstein-Uhlenbeck. J. Econ. Finance Adm. Sci. 21(41), 56-62 (2017)

32. Tang, K., Wei, X.: Index investment and the financialization of commodities. Financ. Anal. J. 68(5), 54-74 (2012)

33. Uhlenbeck, G.E., Ornstein, L.S.: On the theory of the Brownian motion. Phys. Rev. 36, 823-841 (1930)

34. Van den Berg: Calibrating the Ornstein-Uhlenbeck (Vasicek) model. http://www.statisticshowto.com/wp-content/uploads/2016/01/Calibrating-the-Ornstein.pdf

\section{Submit your manuscript to a SpringerOpen ${ }^{\circ}$} journal and benefit from:

- Convenient online submission

- Rigorous peer review

Open access: articles freely available online

- High visibility within the field

- Retaining the copyright to your article

Submit your next manuscript at $\gg$ springeropen.com 